\title{
Investigation of Ready Mixed Concrete Transportation Problem Using Linear Programming and Genetic Algorithm
}

\author{
Gulcag Albayrak ${ }^{a^{*}}$, Ugur Albayrak $^{\mathrm{a}}$ \\ ${ }^{a}$ Department of Civil Engineering, Eskisehir Osmangazi University, Eskişehir, Turkey.
}

Received 26 September 2016; Accepted 28 October 2016

\begin{abstract}
Ready-mixed concrete (RMC) is one of the most common building material for construction industry for nearly all developed and developing countries. Generally, because of the technical requirements, concrete must be mixed in a batch plant and transported to the construction site. There are two important factors affected the cost of RMC: raw material cost and transportation cost. Additionally, transportation cost is also included when determining the unit price of RMC. However, profitability affects adversely in the case of long distance between the plant and construction site. For these reason, distribution of RMC from supply to the demand points with minimum cost is aimed in this study. This work contributes to both modelling and dispatching of RMC as an optimization problem by applying linear and heuristic methods. For this purpose, as an example, an urban area which divided into 7 districts and contained 4 concrete batch plants is discussed. Linear programming and genetic algorithm were applied to solve this problem and compared each other under the same conditions. The result shows linear programming is more efficient for this application because of the limited constraints and variables.
\end{abstract}

Keywords: Optimization; Genetic Algorithm; Mathematical Modeling; Ready-Mixed Concrete.

\section{Introduction}

Concrete is one of the most widely used construction material in the world which was first introduced into the construction industry in the early 20th century. Nowadays, concrete is especially prepared by concrete batch plant according to varied recipes to meet the requirements of the construction site and then transported to the construction site. Therefore this product is called Ready Mixed Concrete (RMC). To expand the service of RMC without establishing high cost batch plant at the construction site, the RMC truck was invented to deliver RMC to the construction site. From the business point of view, the RMC batch plant manager may want to dispatch RMC trucks to different construction sites as many as possible to maximize the production and profits of the plant. In addition to, the necessity of the concrete placement in a limited time supports the importance of distance. RMC usually needs to be cast within 1.5 hour after being produced by the batch plant, which limits the service areas of the RMC batch plant. In addition, because of limited service area, the business competition between RMC batch plants is intense [1].

Optimization is the first technique that comes to mind to solve RMC transportation problems. There are many efficient and flexible models and researches based on optimization techniques in literature that have been proposed to solve RMC production and delivery problems. Especially, in the last decade a number of studies have been conducted using heuristic methods to obtain notable solutions for this problem by researcher. The majority of them are related to scheduling. Lu and Lam [2] focused on how to simultaneously optimize concrete delivery schedules and resource provision for the plant, based on a simulation modeling platform which incorporated a combined discrete event simulation and genetic algorithms to model and further optimize one-plant-multisite RMC plant operations.

Feng and $\mathrm{Wu}$ [3] analyzed factors that impact on the delivery process, then built a model based on genetic algorithms and simulation techniques to find the best dispatch schedule that minimized the total waiting time for trucks

\footnotetext{
*Corresponding author: galbayrak@ogu.edu.tr
} 
at a site, while satisfying the need for deliveries to other sites without interrupting the concrete casting operation. Graham, Forbes and Smith [4] presented a neural network methodology to model the RMC delivery system and found that two and three-layer feed-forward networks provide the best estimates of concrete placing productivity. Naso, Surico, Turchiano and Kaymak [5] developed a detailed model and proposed a metaheuristic approach based on a hybrid genetic algorithm combined with constructive heuristics. Yan, Lai and Chen [6] developed an integrated model that combined RMC production schedules and truck dispatch in the same framework. The model was formulated as a mixed integer network flow problem with side constraints, which was solved by developing a solution algorithm incorporating a mathematical programming solver. Lin, Wang, Huang and Wang [7] provided a detailed formulation of a multi-objective model of the minimal cost of dispatching RMC trucks. Maghrebi and Waller [8] formulated the RMC optimization problem mathematically with two models: Integer programming (without time windows) and mixed integer programming (with time windows). The results of the integer programming and mixed integer programming models were compared with experts' decisions.

\section{Method}

The objective of this paper is to optimize the delivery of RMC. To achieve this goal, these steps are performed:

- Designing the problem as a transportation problem

- Determination of constraints and decision variables

- Building a mathematical model which is appropriate with transportation problem

- Analyzing the model with linear programming and genetic algorithm respectively using Microsoft Solver Foundation.

The transportation problem is a classic operations research problem where the objective is to determine the schedule for transporting goods from source to destination in a way that minimizes the shipping cost while satisfying supply and demand constraints [9].

An ordinary transportation problem has the following components: sources, destinations and weighted edges.

In this paper the transportation problem that we would like to take as an example to compare the outcome of two optimization methods have a set of nodes called sources, which have a commodity available for distribution, and another set of nodes called demand points, which require this commodity. The amount of commodity available at each source and the amount required at each demand point are specified, as well as the cost (especially distance for this paper) of transporting the commodity from each source to each demand point. The problem is to determine the quantity to be transported from each source to each demand point, so as to meet all the requirements at minimum total transportation cost. The commodity of this problem is RMC, the sources are found at concrete batch plants, where the $\mathrm{RMC}$ is produced, and the demand points are the construction sites.

\subsection{Optimization Model Design}

The transportation problem can be usually described using following mathematical model. In particular, it is assumed that the transportation network is given by a set $\bar{A}$ of arcs, where (i,j) $\in \bar{A}$ means that there exists route connecting the provider $\mathrm{i}$ and the demander $\mathrm{j}$.

We denote by $c_{i j}$ the unit shipment cost on the arc $(i ; j)$, by $s_{i}$ the available supply at the provider $i$, and by $d_{j}$ the demand at the demander $\mathrm{j}$. The decision variables are the quantities $\mathrm{x}_{\mathrm{ij}}$ of the commodity that is shipped over the arc (i; j) $\in \bar{A}$ and the problem is to minimize the transportation costs,

Minimize $\sum_{(i, j) \in \overline{\mathrm{A}}} c_{i j} x_{i j}$

Under the natural constraints:

- The supply $\mathrm{s}_{\mathrm{i}}$ at $\mathrm{i}$ should exceed the sum of the demands at all $\mathrm{j}$ such that $(\mathrm{i} ; \mathrm{j}) \in \overline{\mathrm{A}}$, i.e.

$$
\sum_{j:(i, j) \in \overline{\mathrm{A}}} x_{i j} \leq s_{i} \text { for all i, }
$$

- The demand $d_{j}$ at $j$ must be satisfied in the sense that is less or equal the sum of the supplies at all $i$ such that $(\mathrm{i} ; \mathrm{j}) \in \overline{\mathrm{A}}$, i.e.

$\sum_{i:(i, j) \in \overline{\mathrm{A}}} x_{i j} \geq d_{j}$ for all $\mathrm{j}$,

and

$x_{i j} \geq 0$ for all $\mathrm{i}$ and $\mathrm{j}$ 
A transportation problem will have feasible solutions if and only if:

$\sum_{i=1} s_{i}=\sum_{j=1} d_{j}$

\subsection{Genetic Algorithm}

Genetic algorithm is a heuristic evolutionary optimization algorithm based on the Darwin's principle "Survival of the fittest" [10]. Genetic Algorithm (GA) is initiated in 1975 by Holland [11], which is based on the mechanics of natural selection and genetics to search through decision space for optimal solution. There are six components in GA including chromosome structure, initial population, fitness function, selection, genetic operators and termination condition.

GA is started with a set of solutions (represented by chromosomes) called population. Solutions from one population are taken and used to form a new population. The new population will be better than the old one. Solutions which are selected to form new solutions (offspring) are selected according to their fitness value. If their fitness value is more suitable, then they have more chances to reproduce. This is repeated until some condition (e.g. number of populations or improvement of the best solution) is satisfied. This algorithm can be represented as Figure 1.

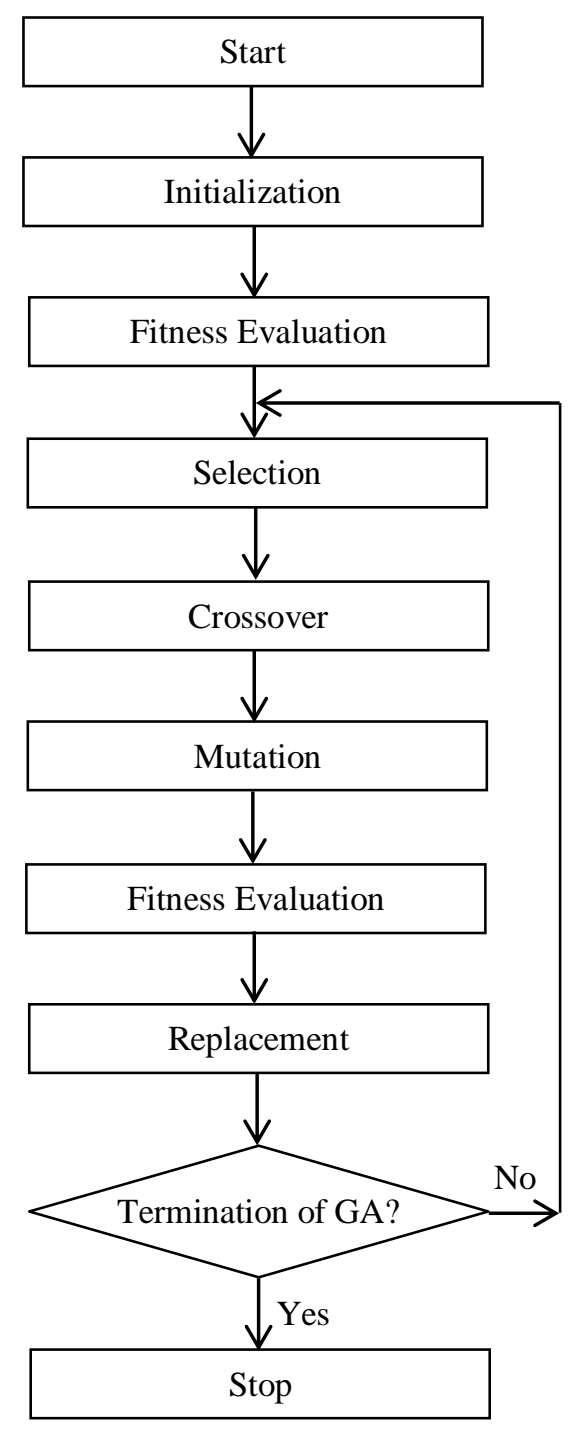

Figure 1. A general flow chart of GA

\subsection{Numerical Example}

A previous study, Albayrak and Albayrak [12] was used for the data of the example. To make the simulation realistic, a metropolitan area consisting of 7 districts is selected according to this article. In this area, there are 4 batch plants that supply concrete for all 7 districts. Concrete demands and production capacity of concrete batch plants are 
created on the basis of actual values which can be reached in a city of Turkey. The annual demand $d_{j}$ involves all types of concrete. In practical, the distance $(\mathrm{km})$ from the batch plant to the center point of regions is described as follows (see Table 1).

Table 1. Distance between suburbans and plants

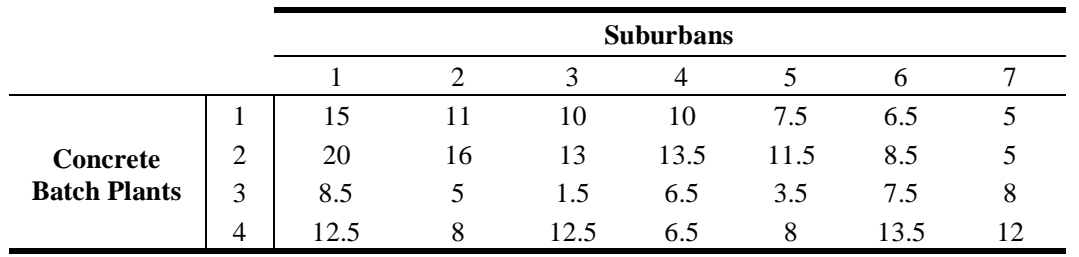

The example has its own systematic approach which breaks down the model to four parts: input parameters, decision variables, constraints and system out.

\section{Decision Variables}

$\mathrm{x}_{\mathrm{ij}}$ refers amount of concrete transported from supply point $\mathrm{i}$ to demand point $\mathrm{j}$. Assume that $\mathrm{i}$ represents the concrete batch plant $(1,2,3,4)$ and $\mathrm{j}$ represents the suburban $(1,2,3,4,5,6,7)$.

\section{Constraints}

The production quantity of the concrete batch plant is indicated by $s_{i}$ and $d_{j}$ denotes the demand of district. In real life, the total production capacity of plant is not usually equal to total demand. Therefore, production quantity can be considered as equal to demand or a dummy demand point can be added to the transportation problem. In this example, number 8 is a dummy destination. Also, as expected, decision variables cannot be negative values. Thus, that is a constraint too. Capacities of the concrete batch plants and demands of districts are shown in Table 2 and Table 3.

Constraints are described as follows:

$\sum_{j=1}^{8} x_{i j} \leq s_{i}$

$\sum_{i=1}^{4} x_{i j} \geq d_{j}$

$\mathrm{x}_{\mathrm{ij}} \geq 0$

Table 2. Capacities of the concrete batch plants

\begin{tabular}{c|cccc}
\cline { 2 - 5 } & \multicolumn{4}{c}{ Concrete batch plants } \\
\cline { 2 - 5 } & 1 & 2 & 3 & 4 \\
\hline $\begin{array}{c}\text { Capacities }\left(\mathbf{s}_{\mathbf{i}}\right) \\
\left(\mathbf{m}^{\mathbf{3}} \mathbf{x 1 0 0 0 / y e a r}\right)\end{array}$ & 1050 & 550 & 800 & 600 \\
\hline
\end{tabular}

Table 3. Demands of the suburbans

\begin{tabular}{c|cccccccc}
\cline { 2 - 7 } & \multicolumn{7}{c}{ Suburbans } \\
\cline { 2 - 8 } & 1 & 2 & 3 & 4 & 5 & 6 & 7 \\
\hline $\begin{array}{c}\text { Demands }\left(\mathbf{d}_{\mathbf{j}}\right) \\
\left(\mathbf{m}^{\mathbf{3}} \mathbf{x 1 0 0 0 / y e a r}\right)\end{array}$ & 550 & 300 & 400 & 350 & 450 & 150 & 300 \\
\hline
\end{tabular}

\section{Objective function}

The purpose is to build a model that covers all demands with the lowest total cost from the sources under the current constraints. Optimizing the quantity of dispatched concrete is important in this problem. Therefore, concrete distribution cost is taken into account as $\$ 1$ per cubic meter in terms of being a unit value.

$$
\operatorname{Minimize} \sum_{(i, j)} c_{i j} x_{i j}
$$




\section{Results}

Primarily, this problem is solved with classical transportation method based linear programming (LP). The equations of the problem are transferred to Excel Solver Foundation, and then solution of the problem is performed. An optimum solution is found which covers all the constraints of demands and sources. The optimum amount of concrete transported from supply point $\mathrm{i}$ to demand point $\mathrm{j}$ can be shown from Table 4.

All demands are found in the greatest possible value i.e. all demands are fully met. In the same way, all source values are calculated at the lowest value. However, plant 1 and 2 are observed that they have excess capacity. The excess capacity $\left(500.000 \mathrm{~m}^{3}\right)$ is assigned number 8 due to use of dummy demand point. The transportation cost of dummy demand is considered as zero. According to results, total cost of the delivering of RMC is $\$ 16.925 .000$ for a year.

Table 4. Results of decision variables $\left(x_{i j}\right)$ of $L P$

\begin{tabular}{cccccccc}
\hline $\mathrm{X}_{11}$ & $\mathrm{X}_{12}$ & $\mathrm{X}_{13}$ & $\mathrm{X}_{14}$ & $\mathrm{X}_{15}$ & $\mathrm{X}_{16}$ & $\mathrm{X}_{17}$ & $\mathrm{X}_{18}$ \\
150 & 50 & - & - & 450 & 150 & - & 250 \\
\hline $\mathrm{X}_{21}$ & $\mathrm{X}_{22}$ & $\mathrm{X}_{23}$ & $\mathrm{X}_{24}$ & $\mathrm{X}_{25}$ & $\mathrm{X}_{26}$ & $\mathrm{X}_{27}$ & $\mathrm{X}_{28}$ \\
- & - & - & - & - & - & 300 & 250 \\
\hline $\mathrm{X}_{31}$ & $\mathrm{X}_{32}$ & $\mathrm{X}_{33}$ & $\mathrm{X}_{34}$ & $\mathrm{X}_{35}$ & $\mathrm{X}_{36}$ & $\mathrm{X}_{37}$ & $\mathrm{X}_{38}$ \\
400 & - & 400 & - & - & - & - & - \\
\hline $\mathrm{X}_{41}$ & $\mathrm{X}_{42}$ & $\mathrm{X}_{43}$ & $\mathrm{X}_{44}$ & $\mathrm{X}_{45}$ & $\mathrm{X}_{46}$ & $\mathrm{X}_{47}$ & $\mathrm{X}_{48}$ \\
- & 250 & - & 350 & - & - & - & - \\
\hline
\end{tabular}

In addition to, linear programming, GA is built to balance the production of the construction sites and the batch plants. The population size and mutation rate are defined respectively 100 and 0.075 . Likewise, all demands are fully met, but the outcomes are different. Total cost of the delivering of RMC is calculated s \$20.050.000.The values of the decision variables are given below (Table 5).

Table 5. Results of decision variables $\left(x_{i j}\right)$ of GA

\begin{tabular}{llllllll}
\hline $\mathrm{X}_{11}$ & $\mathrm{X}_{12}$ & $\mathrm{X}_{13}$ & $\mathrm{X}_{14}$ & $\mathrm{X}_{15}$ & $\mathrm{X}_{16}$ & $\mathrm{X}_{17}$ & $\mathrm{X}_{18}$ \\
- & - & - & - & 100 & 150 & 300 & 500 \\
\hline $\mathrm{X}_{21}$ & $\mathrm{X}_{22}$ & $\mathrm{X}_{23}$ & $\mathrm{X}_{24}$ & $\mathrm{X}_{25}$ & $\mathrm{X}_{26}$ & $\mathrm{X}_{27}$ & $\mathrm{X}_{28}$ \\
- & - & - & 200 & 350 & - & - & - \\
\hline $\mathrm{X}_{31}$ & $\mathrm{X}_{32}$ & $\mathrm{X}_{33}$ & $\mathrm{X}_{34}$ & $\mathrm{X}_{35}$ & $\mathrm{X}_{36}$ & $\mathrm{X}_{37}$ & $\mathrm{X}_{38}$ \\
- & 250 & 400 & 150 & - & - & - & - \\
\hline $\mathrm{X}_{41}$ & $\mathrm{X}_{42}$ & $\mathrm{X}_{43}$ & $\mathrm{X}_{44}$ & $\mathrm{X}_{45}$ & $\mathrm{X}_{46}$ & $\mathrm{X}_{47}$ & $\mathrm{X}_{48}$ \\
550 & 50 & - & - & - & - & - & - \\
\hline
\end{tabular}

\section{Conclusion}

The concrete is mixed just-in-time before the loading of the vehicle at the plant, or the raw materials are poured into the vehicle and are mixed on the way to the construction site. In brief, concrete is a perishable good which cannot be stored or produced in advance. Moreover after being blended the good cannot be transported for more than 1.5 hours [12]. Therefore, transportation algorithm which emphasis on the point of the lowest delivering cost is used in this paper.

The described model and solution method are sufficiently flexible to be enhanced for typical real world requirements. At the same time, practical application of the basic model shows that because of the central management of RMC is more advantageous than the traditional way.

In this paper, the mathematical model which is built for optimization is used. Both of techniques satisfy the balance between the supply and demand of RMC. However, LP obtained the exact solution and the minimum value for 
delivering RMC. The difference between these two methods is that GA does not assure the optimum solution for all problems. In contrast to LP, GA is capable of searching the optimal value instead of the optimum. In heuristic methods, even though the results achieved by these techniques are acceptable, there are still many problems in mathematical modelling that threaten the reliability of the techniques. Also the heuristic methods are powerful tools, especially the problems have uncertainties.

\section{References}

[1] Feng, C. W., Cheng, T. M. and Wu, H. T., Optimizing the schedule of dispatching RMC trucks through genetic algorithms, Automation in Construction, 13 (3). (2004), 327-340.

[2] Lu, M. and Lam, H. C., Optimized concrete delivery scheduling using combined simulation and genetic algorithms, Proceedings of the 37th conference on Winter Simulation Conference. Orlando. USA, 2005.

[3] Feng, C. W. and Wu, H. T., Integrating fmGA and CY-CLONE to optimize the schedule of dispatching RMC trucks, Automation in Construction, 15 (2), (2006), 186-199.

[4] Graham, L. D., Forbes, D. R. and Smith, S. D., Modeling the ready mixed concrete delivery system with neural networks, Automation in Construction, 15 (5), (2006), 656-663.

[5] Naso, D., Surico, M., Turchiano, B. and Kaymak, U., Genetic algorithms for supply-chain scheduling: a case study in the distribution of ready-mixed concrete, European Journal of Operational Research, 177 (3), (2007), 2069-2099.

[6] Yan, S., Lai, W. and Chen, M., Production scheduling and truck dispatching of ready mixed concrete, Transportation Research. 44 (1). (2008), 164-179.

[7] Lin, P. C., Wang, J., Huang, S. H. and Wang, Y. T., Dispatching ready mixed concrete trucks under demand postponement and weight limit regulation, Automation in Construction, 19, (2010), 798-807.

[8] Maghrebi, M. and Waller, S. T., Assessing the accuracy of expert-based decisions in the dispatching of ready mixed concrete, Journal of Construction Engineering and Management, 140(6), (2014), 06014004-1 - 06014004-7.

[9] Aditya, S., Nideesh, K. T. and Guruprasad, N., Solving the transportation problem for warehouses and dealers in Bangalore City, World Academy of Science, Engineering and Technology Mathematical and Computational Sciences, 2(1), (2015).

[10] Chandwani, V., Agrawal, V. and Nagar, R., Modeling slump of ready mix concrete using genetic algorithms assisted training of Artificial Neural Networks, Expert Systems with Applications, 42(2), (2015), 885-893.

[11] Holland, J., Adoption in natural and artificial systems, Ann Arbor, MI: The University of Michigan Press, 1975.

[12] Albayrak, G. and Albayrak, U., Optimization of the ready-mixed concrete delivery system using transportation algorithm, CRC Press, Engineering Optimization IV, The Book Chapter of Numerical Optimization Techniques, 2015, 159-165. 